\title{
Case-control study of severe life threatening asthma (SLTA) in adults: demographics, health care, and management of the acute attack
}

\author{
J Kolbe, W Fergusson, M Vamos, J Garrett
}

Department of Respiratory Medicine, Green Lane Hospital, Auckland, New

Zealand

J Kolbe

W Fergusson

J Garrett

Department of

Medicine, University

of Auckland,

Auckland, New

Zealand

J Kolbe

Department of Psychiatry, John Hunter Hospital, Newcastle, NSW, Australia

M Vamos

Correspondence to: Dr J Kolbe, Respiratory Services, Green Lane Hospital, Auckland, New Zealand

jkolbe@ahsl.co.nz

Received 21 December 1999 Returned to authors 3 March 2000

Revised version received

7 August 2000

Accepted for publication

8 September 2000

\begin{abstract}
Background-Severe life threatening asthma (SLTA) is important in its own right and as a proxy for asthma death. In order to target hospital based intervention strategies to those most likely to benefit, risk factors for SLTA among those admitted to hospital need to be identified. A case-control study was undertaken to determine whether, in comparison with patients admitted to hospital with acute asthma, those with SLTA have different sociodemographic and clinical characteristics, evidence of inadequate ongoing medical care, barriers to health care, or deficiencies in management of the acute attack.
\end{abstract}

Methods-Seventy seven patients with SLTA were admitted to an intensive care unit (pH 7.17 (0.15), $\mathrm{Paco}_{2} 10.7$ (5.0) kPa) and 239 matched controls (by date of index attack) with acute asthma were admitted to general medical wards. A questionnaire was administered 24-48 hours after admission.

Results-The risk of SLTA in comparison with other patients admitted with acute asthma increased with age (odds ratio (OR) $1.04 /$ year, 95\% CI 1.01 to 1.07 ) and was less for women (OR $0.36,95 \%$ CI 0.20 to 0.68 ). These variables were controlled for in all subsequent analyses. There were no differences in other sociodemographic features. Cases were more likely to have experienced a previous SLTA (OR 2.04, $95 \%$ CI 1.20 to 3.45 ) and to have had a hospital admission in the last year (OR 1.86, $95 \%$ CI 1.09 to 3.18). There were no differences between cases and controls in terms of indicators of quality of ongoing asthma specific medical care, nor was there evidence of disproportionate barriers to health care. During the index attack cases had more severe asthma at the time of presentation, were less likely to have presented to general practitioners, and were more likely to have called an ambulance or presented to an emergency department. In terms of pharmacological management, those with SLTA were more likely to have been using oral theophylline (OR 2.14, 95\% CI 1.35 to 3.68) and less likely to have been using inhaled corticosteroids in the two weeks before the index attack (OR $0.69,95 \%$ CI 0.47 to 0.99 ). While there was no difference in selfmanagement knowledge or behaviour scores, those with SLTA were more likely to have inappropriately used oral corticosteroids during the acute attack (OR 2.09, 95\% CI 1.02 to 4.47 ).

Conclusions-In comparison with those admitted to hospital with acute severe asthma, patients with SLTA were indistinguishable on sociodemographic criteria (apart from male predominance), were more likely to have had a previous SLTA or hospital admission in the previous year, had similar quality ongoing asthma care, had no evidence of increased physical, economic or other barriers to health care, but had demonstrable deficiencies in the management of the acute index attack. Educational interventions, while not losing sight of the need for good quality ongoing care, should focus on providing individual patients with better advice on self-management of acute exacerbations. (Thorax 2000;55:1007-1015)

Keywords: life threatening asthma; socioeconomics; health care; acute attack

Severe life threatening asthma (SLTA) is an important entity in its own right. ${ }^{1}$ While still numerically rather small, SLTA greatly outnumbers asthma deaths. ${ }^{1-3}$ Patients with SLTA are a disproportionate source of subsequent asthma morbidity $^{24-6}$ and health care costs. ${ }^{7}$ Previous SLTA clearly defines a population at increased risk of death or SLTA. ${ }^{2-6}$ Because patients who present with SLTA share demographic and other characteristics with those dying of asthma, ${ }^{1}$ and also because death would almost certainly ensue in those presenting with SLTA in the absence of prompt medical intervention, SLTA may be regarded as a "proxy for asthma death". ${ }^{18}$ However, study of SLTA has some practical advantages. The more complete, detailed, and unbiased information available should facilitate the precise definition of specific risk factors for SLTA (and asthma death), as distinct from the risk factors for simple hospital admission for acute severe asthma. In turn, defining risk factors for SLTA within the population of those admitted to hospital with acute asthma should allow the development of specific interventional strategies to reduce the incidence of serious adverse events.

Poor quality, fragmented medical care, or both, has been cited as a cause of asthma death and near fatal asthma in New Zealand ${ }^{6-12}$ and elsewhere. ${ }^{13-17}$ Although in previous studies we have shown evidence of good quality ongoing 
Table 1 Demographic data and previous asthma morbidity of cases (SLTA), matched hospital controls and community comparison group

\begin{tabular}{|c|c|c|c|}
\hline & $\begin{array}{l}\text { Cases (SLTA) } \\
(n=77)\end{array}$ & $\begin{array}{l}\text { Matched hospital } \\
\text { controls }(n=239)\end{array}$ & $\begin{array}{l}\text { Community } \\
\text { comparison group } \\
(n=100)\end{array}$ \\
\hline \multicolumn{4}{|l|}{ Demographic data } \\
\hline Age & $31.8(11.5)$ & $29.3(9.8)$ & $39.0(6.8)$ \\
\hline Sex ( $\%$ male $)$ & $43 \%$ & $23 \%$ & $36 \%$ \\
\hline \multicolumn{4}{|l|}{ Race } \\
\hline European & $61 \%$ & $54 \%$ & 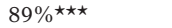 \\
\hline Maori & $17 \%$ & $24 \%$ & 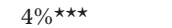 \\
\hline Pacific Island & $19 \%$ & $19 \%$ & $2 \%{ }^{\star \star \star}$ \\
\hline Other & $3 \%$ & $3 \%$ & 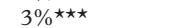 \\
\hline Born outside NZ & $18 \%$ & $23 \%$ & - \\
\hline English first language & $90 \%$ & $91 \%$ & - \\
\hline \multicolumn{4}{|l|}{ Socioeconomic status } \\
\hline 1 & $0 \%$ & $2 \%$ & $12 \%$ * \\
\hline 2 & $9 \%$ & $11 \%$ & $44 \%$ * \\
\hline 3 & $13 \%$ & $15 \%$ & $21 \% \star \star$ \\
\hline 4 & $26 \%$ & $14 \%$ & $7 \%$ * \\
\hline 5 & $8 \%$ & $4 \%$ & $2 \% \star$ \\
\hline 6 & $1 \%$ & $3 \%$ & $0 \% \star$ \\
\hline Home duties & $8 \%$ & $15 \%$ & $9 \%$ * \\
\hline Student & $8 \%$ & $15 \%$ & $3 \%$ * \\
\hline \multicolumn{4}{|l|}{ Previous asthma morbidity } \\
\hline Previous SLTA (ever) & $47 \%$ & $29 \%$ * & 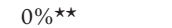 \\
\hline Hospital admission in last year \% & $42 \%$ & $28 \%$ * & $1 \% \star \star$ \\
\hline ED visits in last year & $58 \%$ & $53 \%$ & 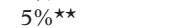 \\
\hline
\end{tabular}

asthma management in patients admitted to hospital with acute asthma, ${ }^{18}$ we have also demonstrated that serious self-management errors occur in a high proportion of patients with acute severe asthma requiring hospitalisation. ${ }^{19}{ }^{20}$ If such errors were a risk factor for SLTA (and asthma death), then educational and other initiatives which specifically focus on management of the acute severe attack may be the most effective means of reducing asthma mortality and severe morbidity.

The aims of this study were therefore to determine whether or not, in comparison with those admitted to hospital with acute asthma, patients experiencing SLTA had (1) different demographic characteristics, (2) inferior health care, (3) barriers to health, and/or (4) demonstrably inferior self-management of the acute attack.

\section{Methods}

A case-control study was undertaken because of its efficiency. ${ }^{21}$

CASES

Cases comprised consecutive patients aged 15-49 years normally resident in the Auckland region who were admitted to one of the two intensive care units (ICUs) in the region with SLTA. ${ }^{1}$ For the purposes of this study, SLTA was defined as admission to ICU for acute severe asthma plus at least one of the following: (1) cardiorespiratory arrest, (2) requirement for mechanical ventilation, (3) impaired level of consciousness at presentation, (4) $\mathrm{pH}<7.2$, and (5) arterial carbon dioxide tension $\left(\mathrm{PaCO}_{2}\right)$ $\geqslant 6.0 \mathrm{kPa}$.

Exclusion criteria were: (1) age $\geqslant 50$ years to avoid major inaccuracies in the diagnosis of asthma in older patients; (2) age $<15$ years as this is the lower age limit for entry into "adult" clinics and patients aged 15 years and older are generally considered to be of sufficient maturity to assume responsibility for their own health, thus avoiding the need to study the behavioural attitudes and psychosocial features of both parent and child and the parent-child interaction as would be necessary for younger age groups; (3) asthmatics in whom the primary reason for admission to the ICU was not asthma or in whom admission to the ICU was primarily for asthma complications such as pneumothorax rather than SLTA; (4) patients with persisting sequelae of hypoxic encephalopathy preventing completion of questionnaire; and (5) patients whose proficiency in English impaired their ability to complete the questionnaire (lack of proficiency in English was defined as requiring an interpreter when attending a routine doctor's appointment).

CONTROLS

Matched hospital control group

This group comprised patients aged 15-49 years normally resident in the Auckland region admitted with acute asthma to a general medical ward of the same hospital as the case, on the same day as the case, on the day before, or within the subsequent two weeks of admission of the case - that is, day -1 to day 14 . No other matching was undertaken as it was considered that features traditionally matched for such as age and sex may be important risk factors for SLTA. Up to four matched controls were selected for each case in order to maximise efficiency. ${ }^{21}$

Exclusion criteria were: (1) age $\geqslant 50$ years; (2) age < 15 years; (3) asthmatics for whom the primary reason for admission was not acute asthma; and (4) poor proficiency in English

Both cases and controls satisfied the criteria for reversible airflow obstruction-that is, improvement of $\geqslant 20 \%$ in forced expiratory volume in one second $\left(\mathrm{FEV}_{1}\right)$ or peak expiratory flow $(\mathrm{PEF})$ in response to treatment.

\section{Community comparison group}

A random sample of community based asthmatic patients were recruited to provide normative data for asthmatics, to provide a three way comparison for some parameters, and to distinguish between risk factors for hospitalisation and risk factors for SLTA. Potential subjects had been identified in a previous study of the prevalence of adult asthma. ${ }^{22}$

QUESTIONNAIRE

A detailed questionnaire was administered to cases and hospital controls within 24-72 hours of admission to general medical wards by the same research associate (WF). Members of the community comparison group were interviewed at home.

Data collected included: (1) Patient demographics. (2) Indicators of quality of health care including: (a) quality of ongoing asthma specific management (acquisition of PEF meter and written action plan, availability of supply of oral steroids, checking of metered dose inhaler (MDI) technique); (b) accessibility of health care: availability of primary health care for routine appointments and during exacerbations, physical accessibility, cost of health care, financial and other barriers to 
Table 2 Severity and asthma management

\begin{tabular}{|c|c|c|c|}
\hline & Cases (SLTA) & $\begin{array}{l}\text { Matched } \\
\text { hospital controls }\end{array}$ & $\begin{array}{l}\text { Community } \\
\text { comparison } \\
\text { group }\end{array}$ \\
\hline \multicolumn{4}{|l|}{ Severity } \\
\hline Mild & $14 \%$ & $23 \%$ & $36 \% \star$ \\
\hline Moderate & $76 \%$ & $66 \%$ & $64 \%{ }^{\star}$ \\
\hline Severe & $9 \%$ & $11 \%$ & $0 \%$ * \\
\hline \multicolumn{4}{|l|}{ Pharmacological management } \\
\hline Inhaled $\beta$ agonist & $98 \%$ & $100 \%$ & $99 \%$ \\
\hline Oral $\beta$ agonist & $10 \%$ & $9 \%$ & $3 \%$ \\
\hline Other inhaled bronchodilator & $3 \%$ & $3 \%$ & $5 \%$ \\
\hline Oral theophylline & $44 \%$ & $21 \% \star$ & $6 \% \star \star$ \\
\hline \multicolumn{4}{|l|}{ Inhaled corticosteroids $\dagger$} \\
\hline 0 & $32 \%$ & $26 \%$ & $44 \%$ \\
\hline$<1000 \mu \mathrm{g}$ & $35 \%$ & $37 \%$ & \\
\hline $1000-2000 \mu \mathrm{g}$ & $19 \%$ & $20 \%$ & $56 \%$ \\
\hline$>2000 \mu \mathrm{g}$ & $13 \%$ & $16 \%$ & \\
\hline Cromolyn & $0 \%$ & $0 \%$ & $6 \%$ \\
\hline \multicolumn{4}{|l|}{ Possession of: } \\
\hline Peak flow meter & $83 \%$ & $81 \%$ & \\
\hline Written action plan & $59 \%$ & $48 \%$ & \\
\hline Oral corticosteroid supply & $39 \%$ & $45 \%$ & \\
\hline Nebuliser & $35 \%$ & $26 \%$ & \\
\hline Inhaler technique checked (last year) & $54 \%$ & $46 \%$ & \\
\hline GP measured PEF & $84 \%$ & $78 \%$ & \\
\hline See doctor other than GP for asthma & $6 \%$ & $10 \%$ & \\
\hline
\end{tabular}

$\mathrm{PEF}=$ peak expiratory flow

${ }^{\star} \mathrm{p}<0.05,{ }^{\star \star} \mathrm{p}<0.01$ compared with cases.

$\dagger$ Inhaled corticosteroids are expressed as $\mu \mathrm{g}$ beclomethasone dipropionate (BDP) or BDP equivalent.

Table 3 Barriers to health care

\begin{tabular}{|c|c|c|c|}
\hline Ongoing managementt & Cases (SLTA) & $\begin{array}{l}\text { Matched } \\
\text { hospital controls }\end{array}$ & $\begin{array}{l}\text { Community } \\
\text { comparison } \\
\text { group }\end{array}$ \\
\hline \multicolumn{4}{|l|}{ Physical accessibility } \\
\hline Regular GP & $96 \%$ & $98 \%$ & \\
\hline Duration of attendance (years) & $6.9(5.6)$ & $6.7(6.1)$ & \\
\hline Ease of appointment (easy, very easy) & $95 \%$ & $85 \%$ & \\
\hline Time to GP (<1 hour) & $79 \%$ & $80 \%$ & \\
\hline Ease of attendance (easy, very easy) & $89 \%$ & $79 \%$ & \\
\hline \multicolumn{4}{|l|}{ Financial barriers } \\
\hline \multicolumn{4}{|l|}{ General: } \\
\hline Only income social security benefit & $36 \%$ & $22 \%$ & $2 \% \star$ \\
\hline Paid employment & $48 \%$ & $52 \%$ & $-\dagger$ \\
\hline \multicolumn{4}{|l|}{ Asthma specific: } \\
\hline \multicolumn{4}{|l|}{ GP fee: } \\
\hline Usual (NZ\$) & $16.0(9.9)$ & $16.9(10.4)$ & $30.9(9.1)$ \\
\hline After hours $(\mathrm{NZ} \$)$ & $18.4(13)$ & $16.9(10.9)$ & $32.2(12.4)$ \\
\hline Medical insurance & $29 \%$ & $29 \%$ & 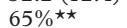 \\
\hline Put off going to GP because of expense & $40 \%$ & $41 \%$ & 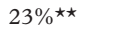 \\
\hline Too expensive to fill prescription & $40 \%$ & $36 \%$ & $13 \%{ }^{\star \star}$ \\
\hline \multicolumn{4}{|l|}{ Doctor-patient relationship } \\
\hline \multicolumn{4}{|c|}{ Wished my doctor talked to me more about my asthma } \\
\hline Strongly disagree/disagree & $57 \%$ & $56 \%$ & $75 \%$ \\
\hline \multicolumn{4}{|l|}{ Have confidence in my doctor's management } \\
\hline Strongly agree/agree & $81 \%$ & $80 \%$ & $51 \%$ \\
\hline \multicolumn{4}{|c|}{ My doctor told me what the medicine would do } \\
\hline & $81 \%$ & $78 \%$ & $82 \%$ \\
\hline \multicolumn{4}{|l|}{ I feel understood by my doctor } \\
\hline Strongly agree/agree & $79 \%$ & $81 \%$ & $87 \%$ \\
\hline
\end{tabular}

${ }^{\star} \mathrm{p}<0.05,{ }^{\star \star} \mathrm{p}<0.001$ compared with cases.

†Data not available from community comparison group

health care; (c) doctor-patient relationship: this is an individual item obtained by factor analysis of the modified Attitudes and Beliefs About Asthma questionnaire. ${ }^{23}$ This modification has been described elsewhere ${ }^{24}$ and has proved to be feasible, reliable, and acceptable in different patient groups. ${ }^{19202425}$ (3) Asthma severity using a modification of the severity classification of asthma based primarily on drug management by Blanc. ${ }^{26}$ (4) Indices of severity of the acute (index) attack. (5) Medication use in the two weeks before admission. (6) Assessment of self-management knowledge using scenarios describing two hypothetical attacks. ${ }^{25}$ One described an attack of increasing severity over seven days (slow onset) while the second described an attack which developed over one hour (rapid onset). Both scenarios ended with the subject "experiencing" a severe attack such that he/she was so wheezy and short of breath as to be unable to speak or rise from a chair. At three stages during each of the scenarios subjects were asked to describe what action they would normally undertake if they were actually experiencing such symptoms. The scoring system, in which scores were weighted for strategies considered most important in aborting an attack or to be potentially lifesaving, was based on consensus statements on the management of asthma published by the Thoracic Society of Australia and New Zealand $(\text { TSANZ) })^{27}$ and the British Thoracic Society (BTS). ${ }^{28}{ }^{29}$ (7) Patient self-management behaviour: this methodology has been described elsewhere. ${ }^{19}$ Behaviour was assessed by a very detailed history of symptoms and selfmanagement strategies undertaken before admission to hospital. Particular attention was paid to symptoms which defined "stages" in the hypothetical scenarios and the selfmanagement strategies undertaken in relation to those stages in the actual attack. The index attack was then classified as rapid ( $<6$ hours) or slow ( $\geqslant 6$ hours). Because of the relative infrequency of rapid onset attacks ( $8 \%$ based on previous findings ${ }^{30}$ ), only those experiencing a slow onset attack were analysed. The subjects' "behaviour" during the index attack was scored using the same system as for the scenarios.

The total possible score for the measures described in (6) and (7) is 25 ; a score of $<15$ was considered to represent clinically significant inadequate self-management knowledge/ behaviour. Serious errors in management were defined using predefined criteria. ${ }^{14}$ Additional information relating to the management of the acute attack was separately obtained-for example, the use of PEF meters, action plans, oral corticosteroids and nebulised bronchodilators, and difficulties experienced during the attack.

The instruments used in (6) and (7) have previously been tested and found to be feasible, acceptable, and reliable in patients attending an asthma clinic, ${ }^{25}$ in inpatients, ${ }^{19}$ and in different ethnic groups. ${ }^{24}$

A detailed assessment of psychological factors will be presented elsewhere. ${ }^{31}$

ETHICS

All subjects gave written informed consent to participate in the study which was approved by the Auckland Healthcare ethics committee.

\section{STATISTICAL ANALYSIS}

Normally distributed data were expressed as mean (SD). For the matched case and controls, conditional logistic regression was performed to identify factors related to SLTA compared with the matched hospital control group. Initially, basic demographic variables were analysed and any statistically significant variables were included in all further analyses. Variables considered to be the best measures of individual parameters were grouped and analysed in conjunction with the significant demo- 
Table 4 Management of the acute attack

\begin{tabular}{|c|c|c|}
\hline & $\begin{array}{l}\text { Cases (SLTA) } \\
(n=77)\end{array}$ & $\begin{array}{l}\text { Matched hospital } \\
\text { controls }(n=239)\end{array}$ \\
\hline \multicolumn{3}{|l|}{ Presentation and management of index attack } \\
\hline \multicolumn{3}{|l|}{ First "port of call" } \\
\hline GP & $29 \%$ & 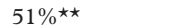 \\
\hline Emergency department & $42 \%$ & $40 \% \star \star$ \\
\hline Ambulance & $30 \%$ & $9 \% \star \star$ \\
\hline \multicolumn{3}{|l|}{ Arterial blood gases } \\
\hline $\mathrm{pH}$ & $\begin{array}{l}7.17(0.15) \\
(\mathrm{n}=75)\end{array}$ & $\begin{array}{l}7.41(0.62)^{\star \star \star} \dagger \\
(\mathrm{n}=148)\end{array}$ \\
\hline $\mathrm{PCO}_{2}(\mathrm{kPa})$ & $10.65(4.98)$ & $4.79(0.98)^{\star \star} \dagger$ \\
\hline Impaired conscious level at presentation & $69 \%$ & $0 \% \star \star \star+$ \\
\hline Mechanical ventilation & $23 \%$ & $0 \% \star \star \star \dagger$ \\
\hline Days in ICU & $1.0(3.1)$ & $0^{\star \star} \dagger$ \\
\hline Days in hospital & $4.8(3.1)$ & $3.3(2.3)$ \\
\hline \multicolumn{3}{|l|}{ Difficulties in management of index attack } \\
\hline Home alone & $10 \%$ & $13 \%$ \\
\hline Lack of telephone & $1 \%$ & $3 \%$ \\
\hline Lack of car & $4 \%$ & $10 \%$ \\
\hline Unable to contact GP & $3 \%$ & $3 \%$ \\
\hline Unable to contact ambulance & $0 \%$ & $4 \%$ \\
\hline Concern about cost & $12 \%$ & $15 \%$ \\
\hline Lack of medications & $16 \%$ & $11 \%$ \\
\hline Lack of knowledge & $14 \%$ & $16 \%$ \\
\hline Bad advice & $0 \%$ & $3 \%$ \\
\hline Panic & $48 \%$ & $33 \%$ * \\
\hline Concern about time off work & $21 \%$ & $31 \% \ddagger$ \\
\hline Other & $35 \%$ & $26 \%$ \\
\hline
\end{tabular}

${ }^{\star} \mathrm{p}<0.02,{ }^{\star \star} \mathrm{p}<0.01,{ }^{\star \star \star} \mathrm{p}<0.001$.

†These factors were used to define "cases".

$\ddagger \mathrm{p}=0.085$. women (OR 0.36, 95\% CI 0.20 to 0.68 ). These variables were therefore controlled for in all further analyses. There were no differences in ethnicity or socioeconomic indicators between cases and hospital matched controls. However, the community comparison group were more likely to be European $(p<0.01)$ and less socioeconomically disadvantaged $(\mathrm{p}<0.05)$ than the cases and matched hospital controls.

Asthma morbidity is also shown in table 1 . Cases with SLTA were more likely than matched hospital controls ever to have had previous SLTA (OR 2.04, 95\% CI 1.20 to 3.45) and to have been admitted to hospital for acute asthma in the last year (OR 1.86, 95\% CI 1.09 to 3.18). The community comparison group had markedly lower morbidity indices than either cases or controls $(\mathrm{p}<0.001$ for all).

The community comparison group was assessed to have less severe asthma than cases or hospital controls (table 2) but there were no differences between cases, hospital controls, or the community comparison group in terms of chronic prescribed drug management of asthma except for the use of oral theophylline (table 2). There were no differences between cases and hospital controls for indicators of quality of ongoing asthma specific medical care (table 2). Data on barriers to health care are shown in table 3. There were no differences between cases and hospital controls in terms of: (1) physical accessibility of health care, (2) financial barriers to health care (both general and asthma specific), and (3) quality of the doctor-patient relationship (either in terms of total factor score (data not shown) or for the individual items). ("Doctor" was defined as the medical professional whom patients considered most important in the management of their asthma.) The community comparison group had fewer financial barriers to health care but less favourable attitudes to their doctor (not statistically significant) (table 3).

Data pertaining to presentation and management of the index attack for cases and matched hospital controls are presented in table 4 . As expected, cases had evidence of more severe asthma at presentation. Cases were less likely to present initially to general practitioners and were more likely to present to emergency departments or to call an ambulance $(\mathrm{p}<0.01)$. Difficulties encountered by the patient in the management of the index attack are shown in table 4. Cases were more likely to have perceived panic during the attack but were less likely to be concerned about time off work. Otherwise there were no differences in these parameters.

Use of oral theophylline (ongoing and in the two weeks before the index attack) was associated with a higher risk of SLTA (OR 2.14, 95\% CI 1.35 to 3.68 ) while use of inhaled corticosteroids in the two weeks before the index attack (as opposed to prescribed inhaled corticosteroids) was associated with a reduced risk of SLTA (OR $0.69,95 \%$ CI 0.47 to 0.99 ) compared with hospital controls. However, cases were less likely to have previously run out of their usual medications $(48 \%$ vs $28 \%$, $\mathrm{p}<0.01)$. There were no differences between 
Table 5 Asthma self-management

\begin{tabular}{|c|c|c|c|}
\hline & Cases (SLTA) & $\begin{array}{l}\text { Matched } \\
\text { hospital } \\
\text { controls }\end{array}$ & $\begin{array}{l}\text { Community } \\
\text { comparison } \\
\text { group }\end{array}$ \\
\hline Run out of medicines (frequently, sometimes) & $48 \%$ & 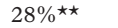 & \\
\hline \multicolumn{4}{|l|}{ Urgent after hours visit } \\
\hline Previous attempt & $53 \%$ & $47 \%$ & \\
\hline No difficulties & $95 \%$ & $93 \%$ & \\
\hline \multicolumn{4}{|c|}{ Previous management of acute nocturnal attack } \\
\hline Rang GP & $4 \%$ & $7 \%$ & \\
\hline Rang locum & $0 \%$ & $1 \%$ & \\
\hline Attended A \& E & $53 \%$ & $52 \%$ & \\
\hline Called ambulance & $31 \%$ & $25 \%$ & \\
\hline "Coped on own" & $86 \%$ & $84 \%$ & \\
\hline \multicolumn{4}{|c|}{ Self-management knowledge (slow onset attack) } \\
\hline Scenario score & $13.2(4.9)$ & $13.4(4.7)$ & $10.5(3.6)^{\star \star}$ \\
\hline Score $\geqslant 15$ & $35 \%$ & $41 \%$ & 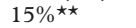 \\
\hline \multicolumn{4}{|c|}{ Self-management knowledge (rapid onset attack) } \\
\hline Scenario score & $15.9(4.1)$ & $15.8(4.6)$ & $11.9(4.7)$ \\
\hline Score $\geqslant 15$ & $71 \%$ & $64 \%$ & 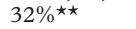 \\
\hline \multicolumn{4}{|l|}{ Self-management behaviour (slow onset attack) } \\
\hline Scenario score & $\begin{array}{l}10.5(4.0) \\
(\mathrm{n}=59)\end{array}$ & $\begin{array}{l}10.1 \\
(\mathrm{n}=230)\end{array}$ & - \\
\hline Score $\geqslant 15$ & $19 \%$ & $14 \%$ & \\
\hline \multicolumn{4}{|l|}{ Index attack use of } \\
\hline Peak flow meter & $27 \%$ & 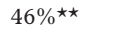 & - \\
\hline Action plan & $27 \%$ & $33 \%$ & \\
\hline Nebulised bronchodilators & $30 \%$ & $27 \%$ & \\
\hline
\end{tabular}

${ }^{\star \star} \mathrm{p}<0.005$ compared with cases.

cases and controls with regard to access to urgent after hours care nor in their previous management of a nocturnal attack (table 5).

There were no differences in selfmanagement knowledge scores or selfmanagement behaviour scores between cases and hospital controls. Cases were less likely to use standard self-management strategies, but only the lower rate of use of a peak flow meter reached statistical significance (table 5). Selfmanagement error in terms of delayed use or non-use of oral steroids during the index attack was associated with an increased risk of SLTA (OR 2.09, 95\% CI 1.02 to 4.47). Delayed or non-summoning of an ambulance was not associated with an increased risk of SLTA.

\section{Discussion}

In comparison with those admitted with acute asthma, patients with SLTA are relatively more likely to be men. However, women predominate in most statistics of asthma morbidity and mortality, making up about $60 \%$ of deaths and SLTA $^{132-37}$ and a greater proportion of hospital admissions (up to $75 \%{ }^{18}$ ), although not all series of asthma death ${ }^{6}$ and of near fatal asthma $^{38} 39$ have shown a predominance of women. We have recently reported a predominance of men in those presenting with rapid onset asthma and who are more likely to have SLTA. ${ }^{29}$ This may be a partial explanation for the relative predominance of men in the SLTA cases. However, sex is not a particularly useful clinical criteria for identifying patients at increased risk of SLTA. Similarly, although there is a statistically significant increased risk of SLTA with increasing age, even within the limited age range studied, an odds ratio of 1.04 per year age is not likely to represent a useful discriminator for identifying patients at increased risk of SLTA or death. These factors were controlled for in all further analyses.

Previous SLTA and recent admission to hospital were risk factors for SLTA whether the comparison was made with matched hospital controls or the community comparison group. This is consistent with previous results from our group ${ }^{4-6}$ and the case-control study of Turner et al, ${ }^{39}$ which was smaller but of similar design to the current study. Risk stratification, even within the group admitted to hospital with acute severe asthma, can therefore be undertaken on the basis of previous SLTA and recent admission to hospital. This is of considerable relevance to all doctors managing patients with acute exacerbations of asthma.

Poor quality and/or fragmented ongoing health care is a potential remediable factor in asthma death ${ }^{61013-17}$ and life threatening asthma. ${ }^{18} 3238$ One of the postulated reasons for the dramatic decline in asthma morbidity and mortality in New Zealand over the last decade is an improvement in the quality of, and access to, primary health care-both ongoing and emergency care. ${ }^{112}$ In a previous cross sectional study of patients admitted to hospital with acute asthma we found evidence of generally good quality, ongoing, asthma specific medical care ${ }^{18}$ but we hypothesised that poor quality care might still be a risk factor for SLTA. However, our results showed that, compared with matched hospital controls, cases with SLTA did not differ in any of the indices of quality of ongoing medical care. Data on quality of health care were not available for the community group and the possibility still exists that deficiencies in health care may operate to increase the risk of an acute attack and admission to hospital, although not increasing the risk of SLTA per se.

Barriers to health care may take a variety of forms-for example, physical inaccessibility, financial barriers, and attitudinal factors. Inaccessibility to health care is one of the reasons why asthma deaths and SLTA are more likely to occur outside usual working hours. ${ }^{1}$ Jones and Bentham ${ }^{40}$ showed that geographical barriers to acute hospital services were an independent risk factor for asthma death, although this association was based on population statistics rather than on data of individuals with asthma. In the current study none of the geographical or organisational factors differed significantly between SLTA cases and hospital controls. Indeed, the data in table 3 argue against an important role for physical barriers in both groups. Analysis of the reasons for difficulty in managing the index attack (table 4) suggests that non-availability of a telephone or a car was not an issue for $>90 \%$ of patients in both groups. However, the current study was undertaken in an urban region, albeit a sprawling one, and thus the results may not be applicable to other regions, particularly if they contain a substantial rural population.

The results of this study do not support the contention that financial barriers to health care are a risk factor for SLTA when comparison is made with hospital controls. This does not imply that financial barriers are not important and operational in patients with asthma, merely that they influence both of these groups in a similar fashion. This is shown in table 3 by the considerable differences between the community group and both cases and hospital controls 
in terms of general and asthma specific financial factors. We have recently demonstrated a very close relationship between hospital admissions, SLTA and asthma death and an index of socioeconomic deprivation (SED) in the Auckland region. ${ }^{41}$ There was a stronger influence of SED on the more severe undesirable adverse outcomes. Although there are no differences between cases (SLTA) and hospital controls in any of the indicators of socioeconomic status, both groups had evidence of significant socioeconomic disadvantage (consistent with results of a previous cross sectional study of patients admitted with acute asthma ${ }^{18}$ ).

Successful management of a chronic illness such as asthma requires the establishment of a therapeutic alliance and partnership between the patient and doctor. Deficiencies in this relationship have adverse effects on the acquisition of self-management knowledge and patient self-management behaviour during an acute attack. ${ }^{19}{ }^{20}$ The doctor's level of sensitivity to the emotional needs of the asthmatic patient may influence clinical decisions; doctors too much in tune with the patient's psychological distress tended to overtreat while doctors who paid inadequate attention to such issues discharged inappropriately early. ${ }^{42}$ In this study all indications were that there was generally an excellent relationship between the patient and the doctor regarded as most important in the management of their asthma, and no evidence that the quality of the doctor-patient relationship was an identifiable risk factor for SLTA.

Factors related to patient self-management strategies shortly before and during the index attack were significantly associated with the risk of SLTA, those with SLTA being (1) less likely to have used inhaled corticosteroids in the two weeks before the index attack, (2) more likely to have used oral theophylline, (3) less likely to have monitored peak flow, and (4) less likely to have appropriately used oral corticosteroids during the acute attack. In part, these results are consistent with our previous results which showed a high rate of errors in the management of severe attacks of asthma, the errors being generally made by the patient rather than the doctor and more likely to occur in relation to strategies that may abort the attack or be potentially life saving. ${ }^{20}$ We have also shown considerable disparity between the patients' knowledge of what to do in the event of an acute attack and what is acutely done-that is, their behaviour. ${ }^{19}$ The patients' selfmanagement knowledge, their behaviour during an acute attack, and self-management errors are all influenced by a variety of socioeconomic and health care factors. ${ }^{19} 2025$ Thus, while deficiencies in quality of ongoing asthma care have been cited as a cause of SLTA/asthma death, ${ }^{1-10}$ efforts directed towards improving patient self-management of acute exacerbations of asthma may be more likely to produce improved outcomes in terms of reductions in asthma mortality and severe morbidity, and should be the focus of intervention strategies and be an essential component of asthma education. ${ }^{43}$
The results of this study raise issues about the perceived role of the general practitioner in the management of acute severe asthma. Cases with SLTA were more likely to present directly to an emergency department or to call an ambulance; only $29 \%$ presented initially to the general practitioner compared with $51 \%$ of hospital controls. Similar reliance on emergency departments was noted in the study by Turner et al. ${ }^{39}$ This behaviour would seem entirely appropriate in the context of a more severe attack of asthma. However, few attacks leading to hospital are rapid ( $<6$ hours) ${ }^{30}$ and the behaviour during the index attack is reflected in the responses to questions on the previous management of nocturnal exacerbations of asthma; only $4 \%$ of those who presented with SLTA and 7\% of hospital controls had telephoned their general practitioner during previous acute episodes. Perhaps most disturbing is the fact that, on previous occasions, over $80 \%$ had not summoned any form of help nor sought any advice. Previous studies have shown that, in the event of an acute attack of asthma, there were delays in summoning emergency services ${ }^{20}$ and also delays in attendance at the emergency department; the latter was indicated by more severe asthma on presentation in Auckland than in Toronto. ${ }^{44}$ This underuse of primary health care, particularly after hours when there may be organisational and other barriers to community care, was one of the factors thought to contribute to asthma morbidity and mortality in New Zealand. ${ }^{19-12}$ These data seem to reflect a perception by the patient of a lack of role for the general practitioner in the management of acute asthma. This may be appropriate in the event of a rapid onset or very severe attack (along with the lower rate of use of a peak flow meter), but may also be influenced by the perceived availability of general practitioners after hours and of other barriers to acute health care (including financial, as primary health care is delivered on a fee-for-service basis in New Zealand). Such patient behaviour needs to be considered when providing advice to individual patients and when devising acute asthma management guidelines. Unfortunately, a similar situation seems to exist for patients admitted to hospital with chronic obstructive pulmonary disease (COPD) as only $25 \%$ had sought medical help from their general practitioner in the two weeks before admission. ${ }^{45}$

One of the major aims of asthma education is to increase patients' self-management knowledge and skills, ${ }^{1925}$ although this does not necessarily translate into improved selfmanagement behaviour. ${ }^{19}{ }^{20}$ In this study there were no differences between cases and controls in the total scores for self-management knowledge (table 5) although scores for both groups were higher than those obtained from a community based comparison group (data not presented). This suggests that educational strategies directed solely at increasing patient knowledge are unlikely to reduce the risk of SLTA. A critical component of selfmanagement educational initiatives is instruction on action to be undertaken in the event of 
an acute attack, specifically the indications for use of oral corticosteroids. Delay or non-use of oral corticosteroids was a risk factor for SLTA, thus reinforcing the importance of that single piece of advice in attempts to reduce serious asthma morbidity.

Inhaled corticosteroids are the linchpin of preventive therapy in adult asthma; these agents modulate the inflammatory response in airways, ${ }^{46-49}$ reduce the level of airway responsiveness, ${ }^{50-52}$ improve various parameters of asthma control,,$^{52-54}$ and reduce asthma morbidity. ${ }^{55}$ Although we have previously shown that the use of all forms of asthma drugs was associated with increased risk of death or SLTA, and that confounding by severity was present, it was only for higher doses of inhaled steroids that the risk ratio (RR) for SLTA or death fell below 1 after adjustment for multiple severity indicators. ${ }^{5}$ Other pharmacoepidemiological studies have reported similar findings of a reduced risk of adverse outcomes in association with the use of inhaled corticosteroids. ${ }^{5657}$ Although the rate of use of inhaled corticosteroids was much higher than in the Canadian study of Turner et $a l^{39}$ this study showed that it was recent use (within two weeks) and not prescribed use that was associated with the reduced risk of a serious adverse event. In view of the similarities in most other respects between the cases and matched hospital controls, these data suggest that recent use of inhaled corticosteroids may prevent SLTA. The importance of the distinction between prescribed and actual use of medications is also highlighted.

In pharmacoepidemiological studies theophylline has been consistently associated with an increased OR for serious adverse events ${ }^{5} 5657$ and, even after adjusting for multiple severity markers, the OR remained significantly raised. ${ }^{5}$ While this may be due to residual confounding (with theophylline use being a marker of poorly controlled asthma for whatever reason or inappropriate medical management), direct or indirect effects of the drug are not excluded. Whatever the mechanism and whatever the indication for administration, the results of this study support the contention that the use of oral theophylline does indicate a patient at increased risk of a serious adverse event.

The lack of information in the literature regarding the possible impact of panic by the patient during the acute attack reflects the general paucity of research in the area of patient behaviour, especially at times when selfmanagement decisions are most crucial. High rates of anxiety, not necessarily related to acute exacerbations, are well documented in those with severe asthma ${ }^{19}{ }^{43}$ and have been shown to be associated with higher rates of hospitalisation and greater use of "as required" medication and oral steroids. ${ }^{58}$ It has been suggested that symptoms of panic/fear occurring during an attack of asthma may lead to more inappropriate action by the patient. ${ }^{5960}$ While heightened awareness may help to focus the patient on making correct self-management decisions, a high level of anxiety/fear may incapacitate the patient and lead to no action rather than incor- rect but deliberate action, precisely what was found to occur in this study and in previous studies. ${ }^{19} 20$

In this study patients admitted to hospital with an acute attack of asthma were used as controls, thus allowing interview of both cases and controls using the same procedure and controlling to a large extent for the impact of the acute exacerbation, drug treatment, and the effect of hospitalisation. Matching, apart from date of attack and hospital of presentation, was not undertaken as it was argued that some of the features traditionally matched for may be significant risk factors. As it turned out, this was entirely appropriate as both age and sex were statistically significant risk factors and were controlled for in all subsequent analyses. While the use of patients admitted acutely to hospital to a large extent controls for severity of asthma ${ }^{45}$ and the effects of acute treatment, the use of hospital controls may represent "overmatching"- that is, the cases and controls were both derived from the same subgroup of asthmatic patients and hence were unlikely to differ in measurable ways. However, the major consideration in the choice of controls was the highly relevant clinical aim to distinguish those at highest risk of SLTA (and death) from the larger group of patients admitted acutely to hospital, rather than distinction from the much larger population of community based asthmatics. In other words, we aimed to distinguish between risk factors for SLTA and risk factors for hospitalisation for acute asthma. Most patients who die of asthma or experience SLTA have had contact with hospital services in the previous year and thus present an opportunity for intervention. ${ }^{4-6}$ Furthermore, any intervention strategies to reduce morbidity and mortality would be likely be hospital based, at least initially.

It has been argued that patients with SLTA to some extent represent a population of survivors and are thus a highly biased sample. ${ }^{8}$ However, during the conduct of this study there were only four asthma deaths in this age range in the region and thus the cases in this study are a reasonably unbiased population of all patients having very severe attacks in the region.

Suitable controls in a case-control study should accurately reflect that population from which the cases were derived. However, obtaining a random sample of patients having an acute exacerbation of asthma in the community presented insurmountable logistical difficulties, not only because of the range of sources of acute health care in New Zealand but also because a substantial proportion of patients do not obtain medical help for an acute attack which occurs outside usual working hours (table 5). The conduct of an epidemiological study of asthma prevalence ${ }^{22}$ provided the opportunity to obtain a random sample of community based asthmatic subjects to provide normative data for some of the instruments used and for comparison with the cases and controls. This comparison reinforced the fact that community based asthmatic 
subjects differ markedly from those who are admitted to hospital with acute asthma.

Although not a primary aim, this study provides data on risk factors for admission to hospital for acute asthma; these included nonEuropean ethnicity, socioeconomic deprivation (either general or directly related to asthma, confirming our previous results ${ }^{1840}$ ), more severe asthma, previous SLTA, and recent admission to hospitals or presentation at the emergency department. This highlights the fact that risk factors for death (and SLTA) may differ according to the control subgroup studied, an important consideration in discussions relating to controlling for severity in the debate about the relationship between fenoterol and asthma deaths. ${ }^{4-6}$

Thus, in comparison with patients admitted to hospital with acute severe asthma, those with SLTA are (1) indistinguishable on sociodemographic criteria (apart from relative male predominance), (2) are more likely to have had previous SLTA or hospital admission in the last year, (3) have similar quality ongoing asthma care, (4) have no evidence of physical, economic, or other barriers to health care, and (5) have demonstrable deficiencies in management shortly before and during the index attack in terms of being more likely to have been using oral theophylline, less prior use of inhaled corticosteroids, less likely to have monitored PEF and to have appropriately used oral steroids during the attack.

These findings have major implications for asthma education and management. Following an acute attack, particularly one of sufficient severity to necessitate admission to hospital, it is important to review carefully the patients' self-management strategies, to identify errors particularly of omission or delays in undertaking appropriate action, and to institute corrective advice. Educational strategies, while not losing sight of the need for good quality ongoing care, need to focus more on providing individual patients with rational, relevant, and realistic advice on self-management of acute exacerbations and this advice needs to be repeatedly reinforced and refined-the " $5 \mathrm{Rs}$ " of asthma education.

The authors wish to thank the medical nursing and other staff of the general medical wards and intensive care units of the Auckland hospitals for their assistance and cooperation during the conduct of this study. We also thank Mrs Josephine Ratnasabapathy for her patience and diligence in preparing the manuscript. We are extremely grateful to Joanna Stewart for her assistance in performing the statistical analyses and to Dr Julian Crane for assistance in the recruitment of the community comparison group.

Funding: This study was supported by grants from Lottery Health Research and New Zealand Health Research Council.

1 Richards GN, Kolbe J, Fenwick J, et al. Demographic characteristics of patients with severe life-threatening asthma: comparison with asthma deaths. Thorax 1993;48:1105-9.

2 Marquette $\mathrm{CH}$, Sauliner F, Le Roy O, et al. Long-term prognosis of near fatal asthma. Am Rev Respir Dis 1992;146:76-81.

3 Ernst P, Spitzer WO, Suissa D, et al. Risk of fatal and nearfatal asthma in relation in relation to inhaled corticosteroid use. $尹 A M A$ 1992;268:3462-4.

4 Garret J, Lanes SF, Kolbe J, et al. Risk of severe life-threatening asthma and $\beta$ agonist type an example of life-threatening asthma and $\beta$ agonist type an ex

5 Rea HH, Garrett JE, Lanes SF, et al. The association between asthma drugs and severe life-threatening attacks. Chest 1996;110:1446-51.
6 Rea HH, Scragg R, Jackson R, et al. A case-control study of deaths from asthma. Thorax $1986 ; 41: 833-9$.

7 Barnes PJ, Jansson B, Klim JB. The costs of asthma. Eur Respir F 1996;9:636-42.

8 Beasley R, Pearce N, Crane J. Use of near-fatal asthma for investigating asthma deaths. Thorax 1993;48:1093-4.

9 Beaglehole R, Jackson R, Sears M, et al. Asthma mortality in New Zealand: a review with more policy implications. $N Z$ Med 7 1989;100:231-4.

10 Sears MR, Rea HH, Beaglehole R. Asthma mortality: a review of recent experience in New Zealand. F Allergy Clin Immunol 1987;80:319-25.

11 Kolbe J, Garrett J, Vamos M, et al. Influences on trends in asthma morbidity and mortality: the New Zealand experience. Chest 1995;106(Suppl):21 1-5S

12 Garrett J, Kolbe J, Richards G, et al. Major reduction in asthma morbidity and continued reduction in asthma mortality in New Zealand: what lessons have been learned? Thorax 1995;50:303-11.

13 Westerman DE, Benatar SR, Potgieter PD, et al. Identification of the high risk asthmatic patient. Experience with 39 patients undergoing ventilation for status asthmatics. Am $\mathcal{F}$ Med 1979;66:565-72.

14 British Thoracic Association. Death from asthma in two regions of England. BMF 1982;285:1251-5.

15 MacDonald JB, Seaton A, Williams DA. Asthma deaths in Cardiff 1963-74: 90 deaths outside hospital. BMF 1976;1: 1493.

16 Miller BD, Strunk RC. Circumstances surrounding the deaths of children due to asthma. A case-control study. Am 7 Child Dis 1989;143:1294-9.

17 Ryan G, Stock H, Musk AW, et al. Risk factors for death in patients admitted to hospital with asthma: a follow-up study. Aust NZ 7 Med 1991;21:681-5.

18 Kolbe J, Vamos M, Fergusson W. Socio-economic disadvantage, quality of medical care and admission for acute severe tage, quality of medical care and admission

19 Kolbe J, Vamos M, Fergusson W, et al. Differential influences on asthma self-management knowledge and self-management behaviour in acute severe asthma. Chest 1996;110:1463-8.

20 Kolbe J, Vamos M, Fergusson W, et al. Determinants of management errors in acute severe asthma. Thorax 1998;53:14-20.

21 Rothman KJ. Types of epidemiologic study. In: Modern epidemiology. Boston: Little, Brown, 1986: 51-76.

22 Crane J, Lewis S, Slater $\mathrm{T}$, et al. The self-reported prevalence of asthma symptoms amongst adult New prevalence of asthma symptoms among
Zealanders. NZ Med 7 1994;107:417-21.

23 Sibbald B, Collier J, D'Souza M. Questionnaire assessment of patients attitudes and beliefs about asthma. Family Pract 1986;3:37-41

24 Vamos M, James F, Kolbe J. Cultural issues facing medical research in New Zealand: short report of an asthma pilot study. NZ Med f 1994;107:132-3.

25 Kolbe J, Vamos M, James F, et al. Assessment of practical knowledge of self-management of acute asthma. Chest 1996;109:86-90.

26 Blanc P. Occupational asthma in a national disability survey. Chest 1987;92:613-7.

27 Woolcock A, Rubinfeld AR, Seale JP, et al. Asthma management plan. Med f Aust 1989;151:650-3.

28 Brewis G. Guidelines for the management of asthma in adults. I. Chronic asthma. BMF 1990;301:651-3.

29 Brewis G. Guidelines for the management of asthma in adults. II Acute severe asthma. BMF 1990;301:797-800.

30 Kolbe J, Fergusson W, Garrett J. Rapid onset asthma: a severe but uncommon manifestation. Thorax 1998;53:2417.

31 Kolbe J, Fergusson W, Vamos M, et al. Case-control study of severe life-threatening asthma (SLTA) in adults: psychological factors. Thorax 2000;55:(in review)

32 Westerman DE, Benator SR, Potgieter PD, et al. Identification of the high-risk asthmatic patient. Am 7 Med 1979;66: $565-72$

33 Cochrane GM, Clark TJH. A survey of asthma mortality in patients between ages 35 and 64 in the Greater London hospitals 1971. Thorax 1975;30:300-5.

34 Ormerod LP, Stableforth DE. Asthma mortality in Birmingham 1975-7: 53 deaths. BMF 1980;687-90.

35 Wasserfallen JB, Schaller MD, Feihl F, et al. Sudden asphyxic asthma: a distinct entity? Am Rev Respir Dis 1990; 142:108-11.

36 Sears MR, Rea HH, Beaglehole R, et al. Asthma mortality in New Zealand: a two-year national study. NZ Med $\mathcal{F}$ 1985;98:271-5.

37 Wareham NJ, Harrison BDW, Jenkins PF, et al. A district confidential enquiry into deaths due to asthma. Thorax confidential enquiry

38 Campbell DA, Luke CG, McLennan G, et al. Near-fatal asthma in South Auckland: descriptive features and medication use. Aust NZ F Med 1996;26:356-62.

39 Turner MO, Noertjojo K, Vedel S, et al. Risk factors for near-fatal asthma. A case-control study in hospitalised patients with asthma. Am f Respir Crit Care Med 1998;157: 1804-9.

40 Jones AP, Bentham G. Health service accessibility and deaths from asthma in 401 local authority districts in England and Wales, 1988-92 Thorax 1997;52:218-22.

41 Garrett JE, Poyser M, Kolbe J. The relationship between social and economic deprivation and asthma morbidity/ mortality in New Zealand. Eur Respir $\mathcal{F}$ 1999;12 (abstract). 
42 Dirks JF, Horton DJ, Kinsman RA, et al. Patient and physician characteristics influencing medical decisions in asthma. F Asthma Res 1979;15:171-8.

43 Kolbe J. Education, action plans, psychological issues and adherence. Can Respir ₹ 1999;6:273-80.

44 Rea HH, Garrett J, Mulder J, et al. Emergency room care of asthmatics: a comparison between Auckland and Toronto. Ann Allergy 1991;66:48-52.

45 Poole PJ, Bagg B, Brodie SM, et al. Characteristics of patients admitted to hospital with chronic obstructive pulmonary disease. NZ Med F 1997;110:272-5.

46 Trigg CJ, Manolitsais ND, Wong $\mathrm{JH}$, et al. Placebocontrolled immunopathologic study for four months of inhaled corticosteroids in asthma. Am f Respir Crit Care Med 1994;150:17-22

47 Sont JK, van Krieken JHJM, Evertse CE, et al. The relationship between the inflammatory infiltrate in bronchial biopsies and clinical severity of asthma in patients treated with inhaled steroids. Thorax 1996;51:496-502.

48 Laitinen LA, Laitinen A, Haaktela T A comparative study of the effects of an inhaled corticosteroid budesonide, and a $\beta_{2}$ agonist, terbutaline, on airway inflammation in newly a $\beta_{2}$ agonist, terbutaline, on airway inflammation in newly
diagnosed asthma; a randomised, double-blind paralleldiagnosed asthma; a randomised, double-blind parallel-
group controlled trial. $\mathcal{f}$ Allergy Clin Immunol 1992;90:3242.

49 Schleimer RP, Beck L, Schwebert L, et al. Reduction of inflammatory cell recruitment by glucocorticoids; cytokines as primary targets. In: Schleimer RB, Busse WW, O'Byrne P, eds. Topical glucocorticoids in asthma: mechanisms and clinical action. New York: Marcel Dekker, 1997 203-38

50 Woolcock AJ, Yan K, Salome CM. Effect of therapy on bronchial hyperresponsiveness in the long-term management of asthma. Clin Allergy 1988;18:165-76.
$51 \mathrm{~K}$ Kerrebijn KF, van Essen-Zandvbet EEM, Neijens HL. Effect of long-term treatment with inhaled corticosteroids Effect of long-term treatment with inhaled corticosteroids children. F Allergy Clin Immunol 1987;79:653-9.

52 Juniper EF, Kline PA, Vanzielegham MA, et al. Effect of Juniper EF, Kline PA, Vanzielegham MA, et al. Effect of
long-term treatment with an inhaled corticosteroid (budesonide) on airway hyperresponsiveness and clinical asthma in nonsteroid-dependent asthmatics. Am Rev Respir Dis 1990;142:832-6.

53 Haaktela T, Jarvinen $M$, Kava $T$, et al. Comparison of a $\beta_{2}$ gonist terbutaline with an inhaled steroid in newly detected asthma. N Engl F Med 1991;325:388-92.

54 Sears MR, Taylor DR, Prent CG, et al. Increased inhaled bronchodilator vs increased inhaled corticosteroid in the control of moderate asthma. Chest 1992;102:1709-15.

55 Donahue JG, Weiss ST, Livingstone JM, et al. Inhaled steroids and the risk of hospitalisation for asthma. $7 A M A$ 1997; 277:887-91.

56 Burgess C, Pearce N, Thiruchelvan R, et al. Prescribed drug therapy and near-fatal asthma. Eur Respir f 1994;7:498-503.

57 Spitzer WO, Suissa S, Ernest P, et al. The use of $\beta_{2}$ agonists pitzer WO, Suissa S, Ernest $\mathrm{P}$, et al. The use of $\beta_{2}$ agonists
and the risk of death and near death from asthma. N Engl f Med 1992;326:501-6.

58 Dirks JF, Horton DJ, Kinsman RA, et al. Patient and physician characteristics influencing medical decisions in asthma. F Asthma Res 1979;15:171-8.

59 Dirks JF, Kinsman RA, Staudenmeyer H, et al. Panic-fear in asthma. Symptomatology as an index of signal anxiety and personality as an index of ego resources. F Neurol Ment Dis 1979;167:615-9.

60 Staudenmeyer H, Kinsman RA, Dirks JF, et al. Medical outcome in asthmatic patient: effects of airways hyperreactivity and symptom-focussed anxiety. Psychosom Med 1979;41: 109-18. 